\title{
Development of an intervention to increase adherence to nebuliser treatment in adults with cystic fibrosis: CFHealthHub
}

\author{
M. A. Arden ${ }^{*}$ (D) M. Hutchings ${ }^{2}$, P. Whelan ${ }^{3}$, S. J. Drabble ${ }^{4}$, D. Beever ${ }^{5}$, J. M. Bradley ${ }^{6}$, D. Hind ${ }^{5}$, J. Ainsworth ${ }^{3}$, \\ C. Maguire ${ }^{5}, H$. Cantrill ${ }^{5}$, A. O'Cathain ${ }^{4}$ and M. Wildman ${ }^{2}$
}

\begin{abstract}
Background: Cystic fibrosis (CF) is a life-limiting genetic condition in which daily therapies to maintain lung health are critical, yet treatment adherence is low. Previous interventions to increase adherence have been largely unsuccessful and this is likely due to a lack of focus on behavioural evidence and theory alongside input from people with CF. This intervention is based on a digital platform that collects and displays objective nebuliser adherence data. The purpose of this paper is to identify the specific components of an intervention to increase and maintain adherence to nebuliser treatments in adults with CF with a focus on reducing effort and treatment burden.
\end{abstract}

Methods: Intervention development was informed by the Behaviour Change Wheel (BCW) and person-based approach (PBA). A multidisciplinary team conducted qualitative research to inform a needs analysis, selected, and refined intervention components and methods of delivery, mapped adherence-related barriers and facilitators, associated intervention functions and behaviour change techniques, and utilised iterative feedback to develop and refine content and processes.

Results: Results indicated that people with CF need to understand their treatment, be able to monitor adherence, have treatment goals and feedback and confidence in their ability to adhere, have a treatment plan to develop habits for treatment, and be able to solve problems around treatment adherence. Behaviour change techniques were selected to address each of these needs and were incorporated into the digital intervention developed iteratively, alongside a manual and training for health professionals. Feedback from people with CF and clinicians helped to refine the intervention which could be tailored to individual patient needs.

(Continued on next page)

\footnotetext{
* Correspondence: m.arden@shu.ac.uk

${ }^{1}$ Centre for Behavioural Science and Applied Psychology, Sheffield Hallam

University, 2.03a Heart of the Campus, Collegiate Crescent Campus, Sheffield

S10 2BQ, UK

Full list of author information is available at the end of the article
}

(c) The Author(s). 2020 Open Access This article is licensed under a Creative Commons Attribution 4.0 International License, which permits use, sharing, adaptation, distribution and reproduction in any medium or format, as long as you give appropriate credit to the original author(s) and the source, provide a link to the Creative Commons licence, and indicate if changes were made. The images or other third party material in this article are included in the article's Creative Commons licence, unless indicated otherwise in a credit line to the material. If material is not included in the article's Creative Commons licence and your intended use is not permitted by statutory regulation or exceeds the permitted use, you will need to obtain permission directly from the copyright holder. To view a copy of this licence, visit http://creativecommons.org/licenses/by/4.0/ The Creative Commons Public Domain Dedication waiver (http://creativecommons.org/publicdomain/zero/1.0/) applies to the data made available in this article, unless otherwise stated in a credit line to the data. 


\begin{abstract}
(Continued from previous page)
Conclusions: The intervention development process is underpinned by a strong theoretical framework and evidence base and was developed by a multidisciplinary team with a range of skills and expertise integrated with substantial input from patients and clinicians. This multifaceted development strategy has ensured that the intervention is usable and acceptable to people with CF and clinicians, providing the best chance of success in supporting people with CF with different needs to increase and maintain their adherence. The intervention is being tested in a randomised controlled trial across 19 UK sites.
\end{abstract}

Keywords: Cystic fibrosis, Adherence, Intervention development, Behaviour change wheel, Person-based approach, Digital intervention, Habit formation

\section{Key messages regarding feasibility}

- In order to develop an intervention to increase adherence to treatment in people with cystic fibrosis $(\mathrm{CF})$, we needed to develop an intervention using behavioural science theory and evidence and informed by people from our target population.

- We developed and refined a complex intervention underpinned by a strong theoretical framework and evidence base. The CFHealthHub intervention is usable and acceptable to people with CF, providing support for people with CF with different needs to increase and maintain their adherence.

- We have a digital platform, intervention manual, and training package for use in the main trial of the CFHealthHub intervention

\section{Background}

Cystic fibrosis (CF) is an inherited genetic condition that affects approximately 10,500 people in the UK and 100, 000 worldwide [1]. The condition causes the build-up of thick sticky mucus in the digestive system and lungs which can result in recurrent lung infections, progressive lung damage, and respiratory failure [2]. People with $\mathrm{CF}$ require a time-consuming regimen of treatment in order to maintain their health $[3,4]$.

There are effective inhaled treatments for CF, usually delivered via a nebuliser, that include antibiotics to reduce infections and mucolytics to thin mucus and to keep airways clear. However, consistent with other longterm conditions, adherence to nebuliser treatments is low [5-7]. Low adherence is associated with increased lung damage and additional need for treatment with intravenous (IV) antibiotics, with higher associated treatment costs $[6,8-11]$, and significant impacts on quality of life [12]. There is a need for effective interventions to increase adherence to treatment in this population.

Interventions have so far shown limited success in increasing adherence in people with CF [13-15]. There are a number of potential reasons for this. First, the interventions may not be targeting the most appropriate factors [16]. Second, there is a lack of studies using a theory and evidence-based approach [17]. Third, interventions may assume that one-size fits all despite evidence that the factors affecting adherence may be person-specific [18]. Even where there have been reported successes, adherence outcomes have not been measured objectively and therefore the findings may not be reliable. Adherence is often measured by either selfreport or medicine possession ratio (MPR). In the UK, objective estimates of median adherence are in the region of 36\% [5], whereas MPR for inhaled therapy are in the region of $65 \%$ [11] and self-report around $80 \%$ [5, 11]. To be sure of success, we need to be able to assess the impact of an intervention on sensitive, objectively measured adherence.

With the advent of nebuliser devices (eTrack ${ }^{\mathrm{m}}$, Pari and I-neb ${ }^{\text {tw }}$, Phillips Respironics) that record time and date stamped treatments and support data transfer, we now have a means to capture objective treatment adherence data. This is important not only as an outcome measure for any intervention, but also to inform patients and clinicians of current adherence, given evidence of the effectiveness of feedback in order to change adherence behaviour [19, 20]. A key aim of the research programme was to develop a digital platform that could capture and display objectively measured nebuliser adherence and 'make adherence visible' and then to develop an associated behaviour change intervention to promote and support increases in adherence and the maintenance of adherence in the longer term. This paper describes the process of the development of the CFHealthHub digital platform and the associated behaviour change intervention to support adherence to nebulised treatment in adults with CF.

\section{Intervention development approach}

The approach to intervention development that we employed was the combined approach identified in a taxonomy of intervention development; a 'theory and evidence-based approach' with a 'target populationbased' approach [21]. The Behaviour Change Wheel $(\mathrm{BCW})[22,23]$ is a theory and evidence-based approach [20] selected because of the need to change the 
behaviour of people with CF. The person-based approach (PBA) to intervention development [24] is a target population-based approach [21] in which feedback from the target population is collected. It is complementary to $\mathrm{BCW}[24]$ and has been previously used alongside the $\mathrm{BCW}$ [25].

The BCW was devised following a systematic evaluation and synthesis of 19 frameworks of behaviour change and considers Capability, Opportunity, and Motivation in relation to Behaviour (COM-B model) [22]. The approach follows three stages: (i) Understanding the behaviour, identifying clear and specific target behaviours, and analysing the factors that impact on that behaviour and the need for change. This stage often uses the complementary Theoretical Domains Framework (TDF) $[26,27]$ that specifies 14 key domains from 33 behaviour change theories, that each influence capability, opportunity, or motivation [22, 28]. (ii) Identifying intervention functions and policy categories, i.e. ways to enact interventions, to achieve behaviour change, and (iii) identifying specific behaviour change techniques (BCTs), i.e. the specific active ingredients to change behaviour as described in the behaviour change technique taxonomy [29], and modes of delivery. The approach incorporates a systematic assessment of the available options and choices and has been widely used in the development of behaviour change interventions in settings including adherence (e.g. [30, 31]).

The PBA was devised from experience of developing digital interventions and utilises mixed methods with people from the target population to inform all stages of the intervention development in an iterative process. Given that we started with a plan to include a digital platform to display adherence data, PBA was an appropriate approach to the development of this digital intervention.

\section{Conceptual framework and aims of the intervention}

We started this intervention development process with some initial ideas about what the intervention might include and the kinds of resources we might have to deliver it. Early work by the team using quality improvement and process mapping [32] had highlighted the need for objective data on medication adherence in CF, and we explored how this could positively impact on clinical practice [3335]. Therefore, we aimed to develop a digital platform that could capture and display objective nebuliser adherence data to patients and clinicians. We understood the important role that the clinical teams play in CF and that adherence support and therefore intervention delivery would be supported by a trained healthcare professional [34].

Early work by members of the team $[36,37]$ had also considered barriers to adherence in $\mathrm{CF}$ and this fed into a conceptual framework of the broad factors influencing adherence and how an intervention might act on these factors to produce and then maintain change. A particular focus of this early work was a consideration of how adherence could be maintained without increasing perceived effort or burden. This conceptual framework drew on the COM-B model and also on other models of adherence and behaviour change and is presented in Fig. 1 (and see [22] p. 81).

The conceptual framework proposes that adherence behaviour is influenced by reflective motivation, i.e. a rational weighing up of the perceived necessity against the perceived concerns about treatment [38]. For some people, an intervention would need to address motivation before any other strategies could be successful since without this people with $\mathrm{CF}$ would not start to initiate attempts to adhere to treatment. Those who want to increase adherence to treatment will make attempts to do so but in many cases these attempts will be hindered by a range of capability and opportunity barriers. An intervention needs to support people to overcome these barriers so that they can adhere to their treatment. Self-regulation is one way in which people can sustain the life-long adherence to preventative inhaled treatment required to maintain lung health. However, there is evidence that self-regulation is difficult to maintain [39] and requires effortful self-control [40] and self-regulatory capacity [41]. Habit theory [42] proposes that habits formed through regular repetition of a specific behaviour in response to a cue over time (initially maintained through self-regulation) comes to trigger the behaviour (automatic motivation) such that habit strength then predicts the likelihood of the behaviour and motivation-driven self-regulation becomes less important. Habits have been proposed to be one of the key mechanisms by which behaviour change can be maintained in the longer term [43] with less perceived effort and burden, and thus a key aim of the intervention is to promote habit formation.

Having a conceptual framework from the start of the project provided a structure that guided intervention development. We recognised the potentially important role of capability, opportunity, and motivation and the overall aim of the intervention. However, we needed to understand the specific barriers and facilitators to adherence for people with $\mathrm{CF}$ and how we could best develop an intervention within this conceptual framework that would enable people to adhere and make habits.

\section{Methods}

\section{The team}

The core intervention development team included people with different perspectives, skills, and expertise: MA is a health psychologist with expertise in the development of theory-based behaviour change interventions. PW is a computer scientist and health informatician with expertise in the design and development of digital health platforms. SD and AOC are health services researchers with experience in undertaking qualitative research with behaviour change interventions. $\mathrm{MH}$ and JB 


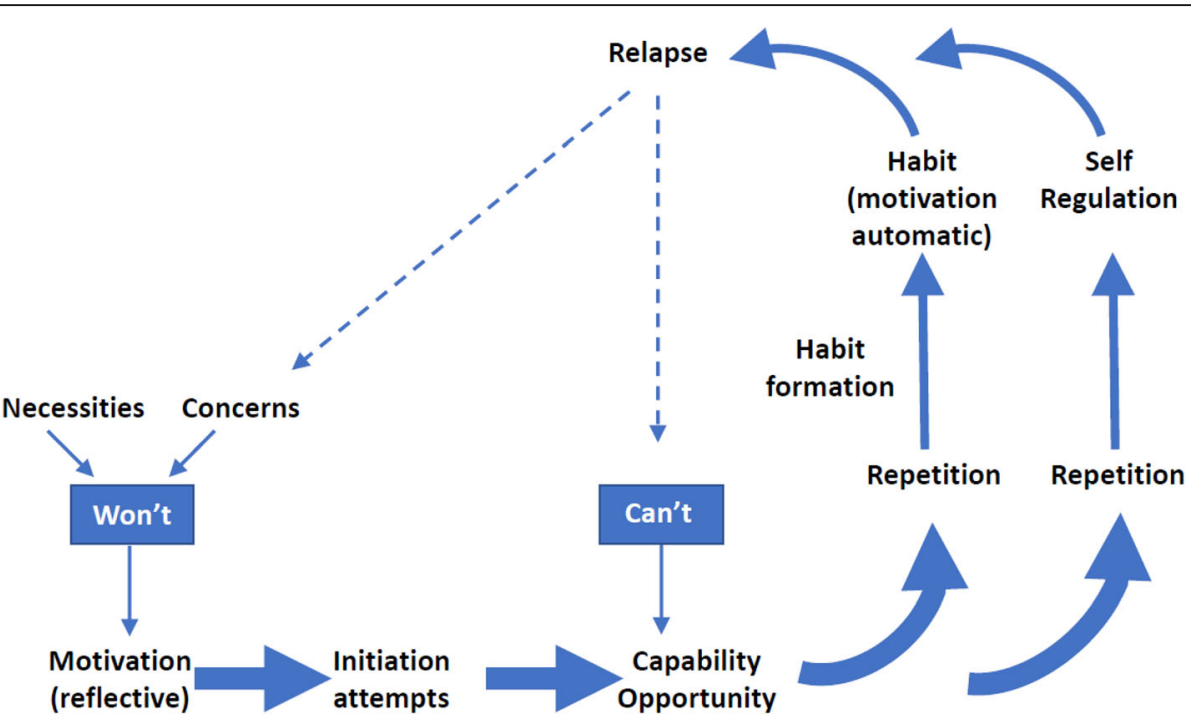

Fig. 1 Conceptual framework for sustained adherence to treatment

\begin{tabular}{|c|c|c|c|c|c|c|}
\hline \multirow[b]{2}{*}{$\begin{array}{l}\text { Technical software } \\
\text { development }\end{array}$} & \multirow{2}{*}{$\begin{array}{c}\text { Stage 1: Planning } \\
\text { Pre-scoping }\end{array}$} & \multicolumn{2}{|c|}{$\begin{array}{l}\text { Stage 2: Designing and } \\
\text { creating the prototype } \\
\text { intervention }\end{array}$} & \multirow{2}{*}{$\begin{array}{c}\text { Stage 3: Iterative } \\
\text { development and } \\
\text { refinement of the } \\
\text { prototype } \\
\begin{array}{c}\text { Iterative software } \\
\text { development }\end{array}\end{array}$} & \multirow[t]{2}{*}{$\begin{array}{l}\text { Stage 4: Documenting } \\
\text { the intervention }\end{array}$} & \multirow{2}{*}{$\begin{array}{c}\text { Stage 5: Further } \\
\text { refinement following } \\
\text { piloting }\end{array}$} \\
\hline & & $\begin{array}{c}\text { Software } \\
\text { development }\end{array}$ & $\begin{array}{l}1^{\text {st }} \\
\text { release }\end{array}$ & & & \\
\hline \multirow[b]{2}{*}{$\begin{array}{l}\text { Behaviour change } \\
\text { wheel intervention } \\
\text { development }\end{array}$} & $\begin{array}{l}\text { Reviewing literature on } \\
\text { adherence in } \mathrm{CF}\end{array}$ & \multirow{2}{*}{$\begin{array}{l}\text { Identification of } \\
\text { intervention } \\
\text { functions, } \\
\text { behaviour change } \\
\text { techniques and } \\
\text { modes of delivery }\end{array}$} & & \multirow[b]{2}{*}{$\begin{array}{l}\text { Refinement of } \\
\text { intervention }\end{array}$} & \multirow{2}{*}{$\begin{array}{l}\text { Development of } \\
\text { intervention manual and } \\
\text { training }\end{array}$} & \multirow[b]{2}{*}{$\begin{array}{l}\text { Further refinement of } \\
\text { intervention }\end{array}$} \\
\hline & $\begin{array}{c}\text { Qualitative study } \\
\text { assessing barriers and } \\
\text { facilitators to adherence } \\
\text { using TDF }\end{array}$ & & & & & \\
\hline \multirow[t]{2}{*}{ PPI } & $\begin{array}{c}\text { Discussion of } \\
\text { social/cultural themes } \\
\text { arising from qualitative } \\
\text { study } \\
\end{array}$ & \multirow{2}{*}{\multicolumn{3}{|c|}{$\begin{array}{l}\text { Demonstration and discussion about development } \\
\text { website/intervention and feedback }\end{array}$}} & & \\
\hline & $\begin{array}{l}\text { Email input into what } \\
\text { the intervention needs } \\
\text { to include }\end{array}$ & & & & & \\
\hline \multirow{3}{*}{$\begin{array}{l}\text { Person based approach } \\
\text { to intervention } \\
\text { development }\end{array}$} & \multirow{3}{*}{$\begin{array}{l}\text { Qualitative study } \\
\text { assessing social and } \\
\text { cultural issues and } \\
\text { barriers related to } \\
\text { adherence }\end{array}$} & & & $\begin{array}{l}\text { Quantitative data from } \\
\text { patients receiving the } \\
\text { intervention }\end{array}$ & & Interviews with patients \\
\hline & & & & $\begin{array}{l}\text { Interviews with patients } \\
\text { receiving the } \\
\text { intervention }\end{array}$ & & $\begin{array}{l}\text { Quantitative and click } \\
\text { analytic data }\end{array}$ \\
\hline & & & & $\begin{array}{l}\text { Think aloud } \\
\text { interventions during use } \\
\text { of CFHealthHub }\end{array}$ & & \\
\hline \multirow{2}{*}{$\begin{array}{l}\text { Healthcare professional } \\
\text { input }\end{array}$} & $\begin{array}{l}\text { Information about } \\
\text { practicalities of delivery }\end{array}$ & & & \multirow{2}{*}{$\begin{array}{l}\text { Interviews with } \\
\text { clinicians }\end{array}$} & & \multirow[t]{2}{*}{ Interviews with clinicians } \\
\hline & $\begin{array}{l}\text { Survey of barriers to } \\
\text { adherence and solutions }\end{array}$ & & & & & \\
\hline
\end{tabular}


are research physiotherapists with expertise in respiratory health and supporting patients with CF with their adherence. MW is a consultant in respiratory medicine working with adults with CF and with expertise in quality improvement. DB has cystic fibrosis and is a health services researcher and co-ordinated the patient and public involvement (PPI) group.

\section{Dynamic and iterative approach}

Intervention development is not a simple linear process. Different methods and actions are taken at different stages but they are used in a dynamic way in that they overlap and are revisited throughout the process [44]. The team followed an intervention development process with stages that fed into each other as illustrated in Fig. 2. Software development used the Agile process [45]. This involved the continuous delivery of working software to meet the shifting requirements identified by the intervention development team. The process required close collaboration between the technical and intervention development teams.

Ethical approval was gained for all studies [REC references: 15/YH/0332; 15/WS/0089] and all participants gave written informed consent.

\section{Stages of development}

There are seven identified domains of actions taken across different approaches to intervention development: conception, planning, designing, creating, refining, documenting, and planning for future evaluation [21].

\section{Stage 1: Planning}

\section{Understanding practicalities of delivery}

Input from members of the team working in the NHS context enabled us to understand that the intervention would need to be delivered flexibly by different members of the multidisciplinary team (MDT) or by health professionals recruited from outside of the MDT, due to NHS shortages in staff [46]. Thus, the intervention that was developed needed to be able to be delivered by a range of health professionals in order to ensure that future implementation was feasible.

\section{Understanding the behaviour}

We undertook a needs analysis for the intervention informed by the following.

Literature review We reviewed the literature to identify key barriers to nebuliser adherence in adults with CF. This included a systematic review of qualitative studies [47], and we updated our knowledge with key papers published during the course of the development phase (e.g. [48]).
Qualitative research with patients We conducted semistructured interviews with 18 adults with cystic fibrosis from a single CF centre in the UK sampled by objective adherence, gender, age, and deprivation index. The data-prompted interviews [49] included the presentation of a graph showing each person their nebuliser adherence data over the last 6 months. The topic guide was informed by the literature review and based around understanding adherence in the context of cystic fibrosis and life in general, and the COM-B model [22] and TDF [26]. The data from these interviews were analysed using two different approaches; a framework analysis using the TDF, including a comparison of factors identified by higher and lower adherence [50], and a discursive analysis [51].

Survey with health professionals We consulted health professionals to understand their perceptions of the barriers to adherence and possible solutions to address those barriers. Fourteen clinicians working at five adult CF centres across the UK were sent an email survey which was completed and returned by six clinicians.

PPI Findings and interpretation of the interviews were provided to the patient co-applicant who led the PPI group to ensure that they were plausible and realistic. DB was involved from a very early stage in discussions around the proposed intervention, including the rationale for its use, as well as the design and functionality of the proposed website.

\section{Stage 2: Designing and creating the prototype intervention}

Stage two of the intervention development process involved the development of a prototype intervention. There were two parts to the CFHealthHub intervention: (i) the digital platform displaying adherence data and online content and tools and (ii) the interventionistdelivered aspects of the intervention delivered during contact with a health professional. Frequent meetings of the intervention development team, informed by parallel discussions of the patient and public involvement group, were held during stages 2 and 3 . At these meetings, we discussed input from each of the following activities.

\section{Design of the prototype intervention using the Behaviour Change Wheel approach}

Following the Behaviour Change Wheel approach ${ }^{1}$, we mapped intervention functions and behaviour change techniques to the identified needs of the intervention. Options were considered and discussed during meetings of the intervention development team, and decisions

\footnotetext{
${ }^{1} \mathrm{We}$ omitted the selection of policy categories stage of the $\mathrm{BCW}$ process as the decision to focus on service provision had been made previously during the development of the programme aims.
} 
were informed by the APEASE criteria [23]: affordability refers to the cost of the intervention, which must be within budget; practicability refers to the extent to which the intervention can be delivered as designed to the target population; effectiveness/cost-effectiveness refers to effectiveness of the intervention in a real-world context in relation to that which is most cost-effective; acceptability refers to the extent to which the intervention is judged to be appropriate by different stakeholders; sideeffects/safety includes unintended consequences of the intervention; and equity refers to the extent to which the intervention impacts on disparities in living standards, health, and wellbeing. We also considered the mode of delivery of each of the behaviour change techniques, whether they were delivered via the digital platform or whether they were delivered by a health professional acting as an interventionist. $\mathrm{MH}$, a physiotherapist experienced in the delivery of adherence support in CF care, informed the development of the interventionistdelivered components.

\section{Design of the CFHealthHub digital platform}

The first phase of technical development was to develop the process and mechanisms by which inhalation data (time-stamped nebulisations) could be automatically captured from third party devices and software, transferred securely, and displayed in a usable way on a digital platform in relation to prescription data (i.e. treatment taken/treatment prescribed). The data transfer flow is shown in Fig. 3. From the eTrack nebuliser, inhalation data was automatically sent to a Qualcomm Life 2net Hub located in the participant's home. Data was transferred from the Qualcomm Hub to a secure server maintained by Pari and then forwarded on to the CFHealthHub server for display and use in the CFHealthHub digital platform. Data transfer was in realtime and required no additional actions by the participant over and above normal nebuliser usage, assuming all devices maintained connectivity with the required networks. This phase also involved a 6-week development and testing phase, where the data transfer mechanism was tested, and the data quality of the transmitted data was validated (see Fig. 2, prototype intervention 1). This was refined over a number of iterations. The need for specific content and tools that arose from the intervention development work fed into further technical developments and prototype releases.

\section{Stage 3: Iterative refinement of the prototype using the person-based approach}

Five participants were people with CF who were aged 16 or older, on the CF registry, provided with an eTrack nebuliser and Qualcomm hub, and given access to the CFHealthHub platform in order to assess the ability of

\section{ris CFHealthHub}

1. Located in homes of PWFC

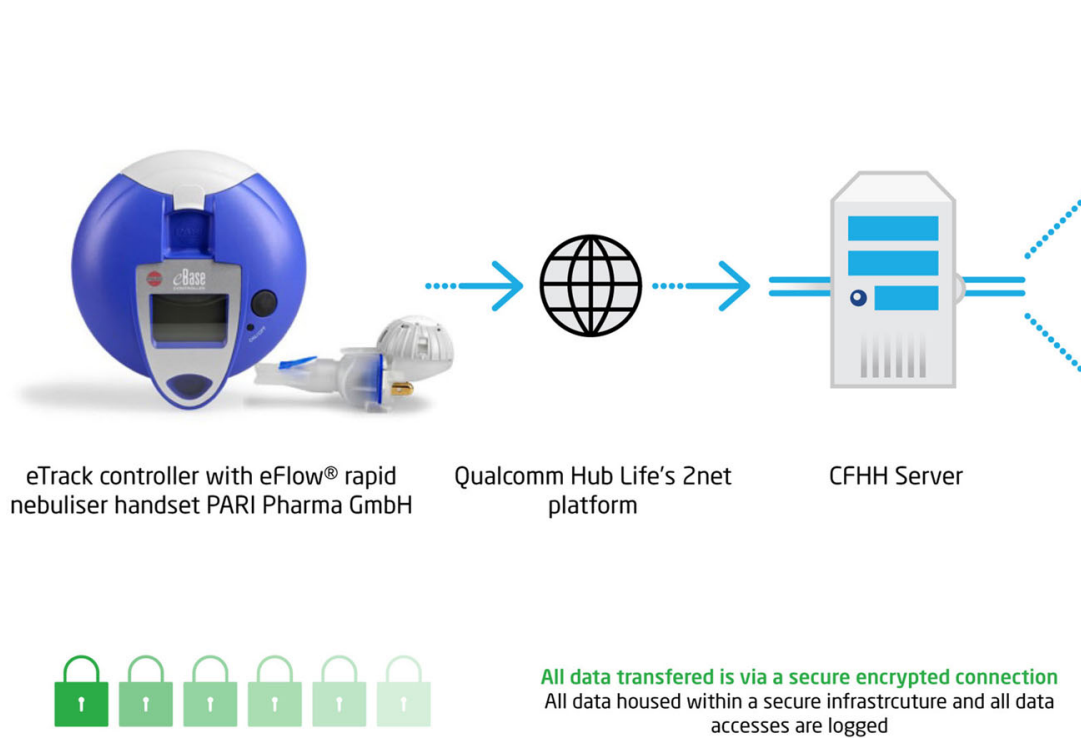

Fig. 3 Data transfer flow
CFHealthHub

Servers

3 Clinician \& Patient Access: Web \& Mobile

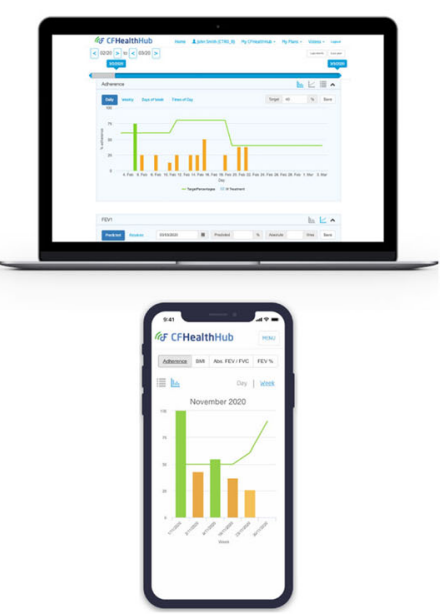

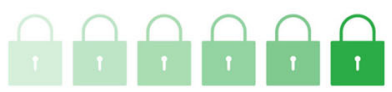


the system to successfully record and display nebulisations. They were followed up after 1 week to troubleshoot any data upload issues and interviewed after a period of 1 month to give them time to use the prototype intervention.

Twenty-two participants were recruited into the iterative development study. Participants were people with $\mathrm{CF}$ who were aged 16 or older, on the CF registry, and willing to take inhaled mucolytics via a chipped nebuliser (eTrack). They were provided with an eTrack nebuliser and Qualcomm hub. They received four sessions of intervention delivery from a physiotherapist and were given independent access to the CFHealthHub web platform. We conducted 18 semi-structured telephone interviews with participants in different cycles of the software development (see Fig. 2, protoypes 1-5) to ask about acceptability of the appearance and functionality of the digital platform and potential improvements. Additionally, we conducted six in-depth think aloud interviews [52, 53] with participants whilst they were using a version of the CFHealthHub website. The screen and audio of the interview was recorded using Camtasia ${ }^{\text {Tw }}$ software. This allowed the software team to identify technical and navigational issues with the website that were corrected in subsequent releases. We also interviewed the physiotherapist delivering the intervention at two time points for wider views about how to deliver the intervention to patients and how that linked to the clinician view of the website.

\section{PPI}

Input was provided by $\mathrm{DB}$ and wider PPI reference group throughout the early development phase of the intervention. Initially, this involved providing input into the proposed content for the textual parts of the website, in terms of the type and level of information that was felt appropriate, not only for people with $\mathrm{CF}$, but others involved in their care.

As the digital platform was developed, PPI input was again provided at regular intervals. Members of the PPI reference group were given the opportunity, on a number of separate occasions, to explore iterations of the website through a demonstration version of the website. Feedback was then provided in meetings of the group, which was then passed back to the wider study team.

Aside from input on the design, group members also provided comment on practical issues around data sharing within the website, and the user guide that had been produced to accompany it.

\section{Stage 4: Documenting the intervention}

At the end of this process, in readiness for the pilot trial, we created an intervention manual that outlined the key components of the intervention, how to use the CFHealthHub digital platform, and the manner and structure of delivery, and an associated training programme for interventionists as well as a user guide for participants.

\section{Stage 5: Further refinement of the intervention following piloting}

Whilst descriptions of the intervention development process often stop before piloting and feasibility testing $[44,54]$, we utilised the pilot and feasibility study [55] to identify further refinements that were made to the intervention before it was used in the final randomised controlled trial.

The pilot and feasibility study consisted of a mixed methods process evaluation undertaken concurrently with a pilot RCT in two UK CF centres. Participants were people with $\mathrm{CF}$ who were aged 16 or older, on the CF registry, and willing to take inhaled mucolytics and/ or antibiotics via an eTrack nebuliser. Three interventionists were trained to deliver the intervention in six face-to-face meetings over 5 months to 32 participants who had access to the CFHealthHub (CFHH) website throughout. We conducted 25 semi-structured face-toface interviews with patients in the intervention arm of the RCT $(n=14)$, interventionists delivering the intervention ( $n=3$ at 2 time points), and members of the wider multidisciplinary team (MDT) $(n=5)$.

The findings from the quantitative [55] and qualitative [56] aspects of the study were triangulated [57] and the implications for the further refinement of the intervention discussed by the development team with input from PPI representatives. As the software was more mature at this stage, changes became more costly in terms of implementation effort and therefore regular prioritisation meetings were conducted where the team agreed on which requirements would be implemented. Decisions about which work to prioritise were made using the MoSCoW criteria of prioritisation: Must have, Should have, Could have, and Won't have [58].

A full description of the intervention was written following the TiDieR (Template for Intervention Description and Replication) checklist [59].

\section{Results}

\section{Stage 1: Planning the intervention}

The research confirmed that different factors influenced different people's ability to adhere and it was therefore important, for reasons of equity, to develop an intervention that addressed multiple capability, opportunity, and motivation barriers to adherence. Our behavioural needs analysis enabled us to identify the factors that the intervention needed to address (see Table 1) and the team considered and discussed whether the intervention should be designed to address each of these needs. Three domains were excluded at this stage (see Table 1 for rationale). 
Table 1 Needs analysis by COM-B and TDF with decisions for inclusion/exclusion in the intervention

\begin{tabular}{|c|c|c|c|}
\hline $\begin{array}{l}\text { COM-B } \\
\text { component }\end{array}$ & TDF domain & Needs analysis & Inclusion/exclusion \\
\hline $\begin{array}{l}\text { Physical } \\
\text { capability }\end{array}$ & Physical skills & $\begin{array}{l}\text { Need skills to use nebuliser, prepare treatment, and clean } \\
\text { nebuliser }\end{array}$ & Included \\
\hline \multirow[t]{3}{*}{$\begin{array}{l}\text { Psychological } \\
\text { capability }\end{array}$} & Knowledge & $\begin{array}{l}\text { Need to know about the correct treatment-taking proce- } \\
\text { dures, to understand treatment action and the import- } \\
\text { ance of nebuliser treatment } \\
\text { Need to address treatment concerns }\end{array}$ & Included \\
\hline & $\begin{array}{l}\text { Memory, } \\
\text { attention, and } \\
\text { decision } \\
\text { processes }\end{array}$ & Need to remember to take treatment & Included \\
\hline & $\begin{array}{l}\text { Behavioural } \\
\text { regulation }\end{array}$ & $\begin{array}{l}\text { Need to develop routines, plans, and habits for treatment } \\
\text { Need to monitor adherence behaviour }\end{array}$ & Included \\
\hline $\begin{array}{l}\text { Physical } \\
\text { opportunity }\end{array}$ & $\begin{array}{l}\text { Environmental } \\
\text { context and } \\
\text { resources }\end{array}$ & $\begin{array}{l}\text { Need to have a time, place, and the equipment do take } \\
\text { treatment } \\
\text { Need to develop strategies to take treatment around } \\
\text { specific barriers or times when treatment taking is more } \\
\text { difficult }\end{array}$ & Included \\
\hline $\begin{array}{l}\text { Social } \\
\text { opportunity }\end{array}$ & Social influences & $\begin{array}{l}\text { Need positive support from family, healthcare } \\
\text { professionals, and/or others to do treatment } \\
\text { Need to have social norms for adherence }\end{array}$ & Included \\
\hline \multirow[t]{6}{*}{$\begin{array}{l}\text { Reflective } \\
\text { motivation }\end{array}$} & $\begin{array}{l}\text { Professional/ } \\
\text { social role and } \\
\text { identity }\end{array}$ & $\begin{array}{l}\text { Need to develop a social identify that is consistent with } \\
\text { treatment adherence }\end{array}$ & $\begin{array}{l}\text { Excluded-social identity change in the context of } \\
\text { adherence is not well understood }\end{array}$ \\
\hline & $\begin{array}{l}\text { Beliefs about } \\
\text { capabilities }\end{array}$ & $\begin{array}{l}\text { Need to develop confidence in the ability to take and } \\
\text { adhere to treatment } \\
\text { Need to develop strategies to take treatment at times or } \\
\text { in situations when it is more difficult }\end{array}$ & Included \\
\hline & Optimism & $\begin{array}{l}\text { Need to be optimistic that full treatment adherence is } \\
\text { possible }\end{array}$ & $\begin{array}{l}\text { Excluded_focus on achieving higher but realistic } \\
\text { adherence }\end{array}$ \\
\hline & $\begin{array}{l}\text { Beliefs about } \\
\text { consequences }\end{array}$ & $\begin{array}{l}\text { Need to believe that treatment is effective and necessary } \\
\text { for long-term health, symptom reduction, avoiding IVs/ } \\
\text { hospital stays } \\
\text { Need to believe that treatment is important irrelevant of } \\
\text { perceptions of current wellness } \\
\text { Need to address treatment concerns }\end{array}$ & Included \\
\hline & Intentions & $\begin{array}{l}\text { Need to encourage intentions to adhere to treatment } \\
\text { and avoid periods of intentional non-adherence }\end{array}$ & Included \\
\hline & Goals & $\begin{array}{l}\text { Need goals for treatment adherence } \\
\text { Need to develop strategies to address conflicting goals }\end{array}$ & Included \\
\hline \multirow[t]{2}{*}{$\begin{array}{l}\text { Automatic } \\
\text { motivation }\end{array}$} & Reinforcement & $\begin{array}{l}\text { Need to provide some reinforcement for treatment-taking } \\
\text { Need to address treatment concerns }\end{array}$ & Included \\
\hline & Emotion & $\begin{array}{l}\text { Need to focus on emotional drivers for adherence (fear, } \\
\text { anticipated regret) } \\
\text { Need to address low mood and avoidance }\end{array}$ & $\begin{array}{l}\text { Excluded_not acceptable to focus on fear and may } \\
\text { increase avoidance. Addressing low mood/depression } \\
\text { outside the scope of this intervention (signposting to } \\
\text { other support services) }\end{array}$ \\
\hline
\end{tabular}

\section{Stage 2: Designing and creating the intervention}

The stage 1 analysis indicated that a number of needs were replicated across different TDF domains (e.g. need to address treatment concerns), and the intervention development team therefore generated 'themes of need' for the intervention (see Table 2). The selection of intervention functions matched to each theme of needs is described in Table 2 along with the reasons for inclusion/ exclusion according to the APEASE criteria. Table 2 also displays the selection of behaviour change techniques
(BCTs) to match the needs and intervention functions selected. BCTs that were considered but rejected by the team according to the APEASE criteria are also shown.

Discussions about the intervention considered the needs of different types of patients with different barriers to adherence, as indicated in the analysis of the stage 1 qualitative work. We therefore considered how the intervention could be tailored to meet the needs of individuals and to reduce the possibility of overwhelming an individual with lots of BCTs that might not be useful or 
Table 2 Intervention themes, potential, and selected intervention functions, and potential and selected behaviour change techniques (BCTs)

\begin{tabular}{|c|c|c|c|c|c|}
\hline $\begin{array}{l}\text { Intervention themes } \\
\text { (and associated TDF } \\
\text { domains) }\end{array}$ & $\begin{array}{l}\text { Needs addressed } \\
\text { within module }\end{array}$ & $\begin{array}{l}\text { Intervention functions } \\
\text { included with } \\
\text { description of the } \\
\text { context of use }\end{array}$ & $\begin{array}{l}\text { Intervention functions } \\
\text { considered and } \\
\text { rejected with APEASE } \\
\text { rationale }\end{array}$ & $\begin{array}{l}\text { BCTs selected; } \\
\text { for full } \\
\text { descriptions } \\
\text { of BCTs see } \\
\text { [29] }\end{array}$ & $\begin{array}{l}\text { BCTs considered and } \\
\text { rejected with APEASE } \\
\text { rationale }\end{array}$ \\
\hline $\begin{array}{l}\text { A need to understand } \\
\text { treatment (physical skills, } \\
\text { knowledge, beliefs } \\
\text { about consequences, } \\
\text { intentions) }\end{array}$ & $\begin{array}{l}\text { Need to know about } \\
\text { the correct treatment- } \\
\text { taking procedures, to } \\
\text { understand treatment } \\
\text { action and the import- } \\
\text { ance of nebuliser } \\
\text { treatment } \\
\text { Need to address } \\
\text { treatment concerns } \\
\text { Need to believe that } \\
\text { treatment is effective } \\
\text { and necessary for long- } \\
\text { term health, symptom } \\
\text { reduction, avoiding IVs/ } \\
\text { hospital stays } \\
\text { Need to believe that } \\
\text { treatment is important } \\
\text { irrelevant of }\end{array}$ & $\begin{array}{l}\text { Education (knowledge } \\
\text { on the importance of } \\
\text { treatment-taking even } \\
\text { when well, effectiveness } \\
\text { of treatment, and treat- } \\
\text { ment action) } \\
\text { Persuasion (using } \\
\text { imagery and other } \\
\text { communications } \\
\text { strategies to persuade } \\
\text { about the importance of } \\
\text { consistent long-term } \\
\text { adherence) } \\
\text { Modelling (peers who } \\
\text { have knowledge and } \\
\text { understanding about } \\
\text { nebuliser treatment and } \\
\text { how they adhere) }\end{array}$ & $\begin{array}{l}\text { Coercion-not } \\
\text { acceptable to patients or } \\
\text { health professionals to } \\
\text { focus on punishment for } \\
\text { non-adherence }\end{array}$ & $\begin{array}{l}5.1 \text { Information } \\
\text { about health } \\
\text { consequences } \\
9.1 \text { Credible } \\
\text { source } \\
5.2 \text { Salience of } \\
\text { consequences } \\
6.1 \\
\text { Demonstration } \\
\text { of the } \\
\text { behaviour } \\
\text { 16.3 Vicarious } \\
\text { consequences } \\
\text { 15.4 Self-talk }\end{array}$ & $\begin{array}{l}\text { 5.5 Anticipated regret: } \\
\text { potentially inducing fear } \\
\text { not deemed acceptable } \\
\text { (acceptability) } \\
\text { 9.2 Pros and cons: Not } \\
\text { practical as would take } \\
\text { too long to deliver } \\
\text { within the intervention } \\
\text { (practical) } \\
\text { 9.3 Comparative } \\
\text { imagining of future } \\
\text { outcomes: may be } \\
\text { challenging for some } \\
\text { patients and could } \\
\text { induce fear given life- } \\
\text { limiting nature of CF } \\
\text { (practical, side-effects, } \\
\text { equity). }\end{array}$ \\
\hline
\end{tabular}

A need to be able to monitor adherence (behavioural regulation) perceptions of current wellness

Need to encourage intentions to adhere to treatment and avoid periods of intentional non-adherence

Need to monitor adherence behaviour and outcomes
Education (knowledge about own adherence data)

Environmental restructuring (providing a nebuliser, a hub, and a digital platform to track and provide data on nebuliser adherence) Enablement (providing behavioural support to provide feedback on adherence data)

Enablement (providing behavioural support to set realistic specific goals for treatment) Incentivisation (creating an expectation of rewards when goals are met)
2.3 Selfmonitoring of behaviour 12.5 Adding objects to the environment
2.4 Self-monitoring of outcomes of behaviour: no easy mechanism to monitor symptoms or health and changes may be due to factors other than adherence (practical, side-effects)
A need to have treatment goals and feedback (goals, reinforcement)
Need goals for treatment adherence Need to provide some treatment-taking reinforcement for
Coercion-not acceptable to patients or health professionals to focus on punishment for not meeting goals Modelling-not clear what feedback on others behaviour might be most effective to produce change, and could backfire
1.1 Goal setting 1.3 Goal setting (behaviour) 2.2 Feedback on behaviour 1.6 Discrepancy between current behaviour and goal

1.5 Review behaviour goal 8.7 Graded tasks 10.4 Social reward

A need to have confidence in the ability to adhere to treatment (beliefs about capability, social opportunity)
Need to have social norms for adherence Need to develop confidence in the ability to take and adhere to treatment
Modelling (providing role models of people who have increased their adherence for people to aspire to)

Persuasion (using communication to increase feelings of
Environmental restructuring-not practical to change the environmental barriers that make treatments feel difficult to do Education-not likely to be effective given that
6.1

Demonstration of behaviour

15.1 Verbal persuasion about capability 15.3 Focus on (outcome): the achievement of some outcome goals could be impacted on by factors outside of the individual's control and could result in demotivation (sideeffects) 
Table 2 Intervention themes, potential, and selected intervention functions, and potential and selected behaviour change techniques (BCTs) (Continued)

\begin{tabular}{|c|c|c|c|c|c|}
\hline $\begin{array}{l}\text { Intervention themes } \\
\text { (and associated TDF } \\
\text { domains) }\end{array}$ & $\begin{array}{l}\text { Needs addressed } \\
\text { within module }\end{array}$ & $\begin{array}{l}\text { Intervention functions } \\
\text { included with } \\
\text { description of the } \\
\text { context of use }\end{array}$ & $\begin{array}{l}\text { Intervention functions } \\
\text { considered and } \\
\text { rejected with APEASE } \\
\text { rationale }\end{array}$ & $\begin{array}{l}\text { BCTs selected; } \\
\text { for full } \\
\text { descriptions } \\
\text { of BCTs see } \\
\text { [29] }\end{array}$ & $\begin{array}{l}\text { BCTs considered and } \\
\text { rejected with APEASE } \\
\text { rationale }\end{array}$ \\
\hline & & positive self-efficacy) & $\begin{array}{l}\text { confidence likely to be } \\
\text { based on past } \\
\text { experiences of trying to } \\
\text { adhere and potentially } \\
\text { failing. }\end{array}$ & past success & \\
\hline
\end{tabular}

A need to have a treatment plan (behavioural regulation, memory, attention, and decision processes)
Need to remember to take treatment Need to develop routines, plans and habits for treatment
Environmental restructuring (providing digital tools on which to make and record plans) Enablement (providing behavioural support to identify appropriate plans)
A need to solve problems around treatment adherence (environmental context and resources, goals, social opportunities, beliefs about capability)
Need skills to use nebuliser, prepare treatment, and clean nebuliser Need to have a time place and the equipment do take treatment

Need to develop strategies to take treatment around specific barriers or times when treatmenttaking is more difficult Need to develop strategies to address conflicting goals Need positive support from family, healthcare professionals and/or others to do treatment Need to develop strategies to take treatment at times or in situations when it is more difficult
Training (skills to be able to adhere use and clean nebuliser and mix treatment)

Education (providing knowledge about support services and strategies to overcome barriers to treatmenttaking)

Environmental restructuring (providing digital tools on which to make and record plans, and provide educational information, directly changing the environmental context and resources for some patients where possible) Enablement (providing behavioural support to identify barriers and make plans about how to overcome them or reduce their effects) Modelling (role models of others who have developed strategies to overcome barriers to adherence)

$\begin{array}{lll}\text { Restriction-not } & 1.2 \text { Problem } & 9.3 \text { Comparative } \\ \text { acceptable to require } & \text { solving } & \text { imaginings of future } \\ \text { patients to focus on } & 12.1 & \text { outcomes (practical) } \\ \text { treatment and reduce } & \text { Restructure the } & \\ \text { opportunity to engage } & \text { physical } & \\ \text { in behaviours associated } & \text { environment } & \\ \text { with other goals } & 15.4 \text { self-talk } \\ & 3.2 \text { social } \\ & \text { support } \\ & \text { (practical) } \\ & 4.1 \text { Instruction } \\ & \text { on how to } \\ & \text { perform the } \\ & \text { behaviour } \\ & 6.1 \\ & \text { Demonstration } \\ & \text { of the } \\ & \text { behaviour } \\ & 8.1 \text { Behavioural } \\ \text { practice/ } & \text { rehearsal } \\ & \\ & \\ & \\ & \\ & \\ & \end{array}$

1.4 Action $\quad 1.8$ Behavioural contract: planning writing and signing 8.3 Habit contract would take too formation much time (practical) 7.1 Prompts/ $\quad 15.2$ Mental rehearsal of cues successful performance: not likely to be effective given that it is not treatment taking that is the challenge but adherence in a range of contexts (effective)

\subsection{Comparative} aginings of future patients to focus on 3.2 social on how to the Demonstration 8.1 Behavioural practice/ .

. 
Table 3 Key components of prototype CFHealthHub digital platform versions 1-5

\begin{tabular}{ll}
\hline Version & Key components \\
\hline 1 & Basic adherence display (blue) + basic prescription entry \\
2 & First behaviour change intervention release: includes my treatment, problem solving, and my toolkit \\
& Allows clinicians to add/edit patients \\
& Basic patient analytics included (page clicks) \\
& Action plan tool \\
& Adherence display updates to show treatment times in labels \\
& Enhanced analytics to capture graph views and clicks \\
& Updated designs for my treatment (more lively colours and images) \\
& 24-hour clock used in labels on graphs for clarity about timing of treatments \\
& Clinician report page added \\
& Screening tool added to tailor my treatment \\
& Coping plans added \\
& Finalised revised design and content of my treatment \\
Revised design and content of problem solving \\
Revised design and content of my toolkit
\end{tabular}

nebuliser treatments every day? and I have concerns about my nebuliser treatments. We devised an algorithm to automatically prioritise up to three modules of content for each participant based on their responses to matched items in the BMQ-Specific ${ }^{2}$ [38]. For example, a 'strongly disagree' response to the beliefs statement, This nebuliser treatment protects me from becoming worse, made it more likely that they would be matched to the I'm not convinced that my nebuliser treatment works module. Interventionists could override and change modules if discussions with participants indicated other or changed priorities over the course of intervention delivery identified during review sessions. Following consultations, interventionists could also select specific modules of problem-solving content and videos matched to the specific needs of the participant and place these in the Toolkit area.

The educational/persuasive content of the modules was created to ensure that the information was accessible and meaningful to people with different needs and different perceptions of 'credible sources'. It included simple animated videos of treatment action, patient stories and links to external websites (e.g. CF Trust, NHS) and Cochrane reviews about drug treatments. All of the content was reviewed by the PPI groups and feedback was sought throughout the iterative development process.

We understood that setting specific goals and plans for treatment would only be effective if people were sufficiently motivated to increase their adherence, and if not, then the intervention should follow a different path that replaced goal setting/planning with ensuring a need to understand treatment and confidence building using

\footnotetext{
${ }^{2}$ We also included an additional belief item identified as important in our qualitative work: Nebulised antibiotic treatments are more important for my health than IV antibiotics
}

the modules and videos available on CFHealthHub and open, non-judgmental discussions with patients.

Some aspects of the intervention were less about the tools and content of the $\mathrm{CFHH}$ website and more about how the interventionists interacted with participants. For example, the self-efficacy intervention components required that interventionists focused on times when treatment had been taken rather than times of nonadherence during discussions about treatment graphs.

\section{Stage 3: Refining the intervention}

Feedback from discussions about the behaviour change techniques and the iterative development study fed into both the technical development of the CFHealthHub digital platform and how the intervention would be delivered by health professionals (the interventionist-delivered components). The versions of CFHealthHub that the participants received changed over time as new content and tools were added into the digital platform (see Table 3). Table 4 provides the main feedback from participants and interventionists from this process along with how these were responded to in the development process.

\section{Stage 4: Documenting the intervention}

The final intervention was documented in a manual for interventionists. This included the following sections that focused on motivating health professionals about the value of the intervention as well as the knowledge and skills that they needed to deliver it:

- Description of the overall intervention and the rationale for its development

- Orientation to the CFHealthHub digital platform including the data displays, behaviour change content and tools, and how to use them 
Table 4 Key feedback and decisions from qualitative interviews conducted during iterative development cycles

\begin{tabular}{l} 
Feedback \\
\hline Participants thought blue adherence graphs look and homepage \\
looked too 'NHS' and boring. \\
Some participants liked the picture on the homepage, other did \\
not. There was no consensus about which image was preferable. \\
Some participants requested to personalise with their own images. \\
Participants wanted a forum or some way to interact with other \\
people with CF, to share experiences, problems, and ideas.
\end{tabular}
people with CF, to share experiences, problems, and ideas.

Participants want to instantly see achievements/progress on graphs. Suggested traffic light system. Wanted to see data over a longer time frame

Participants confused by prescription entry. Suggested making this clinician entered with mechanism by which participants can flag if their prescription changes.

Clinicians suggested that it would be useful to be able to see treatment times easily, e.g. when you hover over a bar on the charts.

Some participants go to bed late and their last treatment appears on the following day's graph. Would be useful to be able to modify the time for the end of day to adjust this to meet different lifestyles of patients

\section{Make Rationale/comments}

changes

Accept Changed design to look more distinctly CFHealthHub. More images

Accept Needs to feel like it belongs to the participant. There is no one image that meets the needs of everyone. Images could be of a goal (e.g. upcoming holiday) which could serve to act as a motivator

Reject Concern that this would require moderation (not practical) and that, given that low adherence is very common, could serve to normalise non-adherence and demotivate participants. Instead decided to incorporate 'talking heads' video clips-providing some information from others with CF but where we could control the content.

Accept

Some concern about traffic light system-specifically that too much red would put people off. But suggestion came up frequently. Modified over iterations so that green $=$ hit target, amber $=$ some treatment but not met target, red date $=$ not treatment taken. Participants able to open out data to look over a longer period.

Accept Correct prescription data is vital to success of the intervention as this is what the adherence data is based on. Important to get right.

Accept Clear benefit for both patients and clinicians.

Reject Extensive programming task to change the basic time set up from midnight-midnight day.
- Plans for different types of intervention delivery sessions including how to prepare for them

- Information about how to tailor the intervention to suit different patients' needs

- Intervention delivery using a person-centred approach
An associated training programme for interventionists was developed.

\section{Stage 5: Further refinement following piloting}

The outcomes of the pilot and feasibility study are described in detail elsewhere $[55,56]$. Key outcomes that fed into

Table $\mathbf{5}$ Key feedback and decisions from qualitative interviews conducted during pilot and feasibility study

\begin{tabular}{ll}
\hline Feedback & $\begin{array}{l}\text { Make } \\
\text { changes }\end{array}$ \\
\hline Limited engagement with CFHealthHub outside of visits & Accept
\end{tabular}

with the interventionist

Fewer interventionist sessions were delivered than anticipated

Limited delivery of some key BCTs by interventionists

Changes to the target line changed the target line for all time periods

Lack of faith in the validity of the adherence data by participants and interventionists

Some participants did not want to watch videos of other people with CF. Making social comparisons was threatening.

\section{Rationale/comments}

To address this, we prioritised the development of the CFF app for the trial (must have) and we added tools to encourage engagement, i.e. push notifications sent from the app each Monday congratulating participants on meeting their target or encouraging them to start again. We also added a reminder message sent if $\mathrm{CFHH}$ had not been accessed for a period of 2 weeks.

Accept We devised a clear intervention pathway that indicated the frequency, interval, and pattern of intervention sessions for each participant for the trial.

Accept Modify interventionist training and handbook and create worksheets to follow. Monitor delivery of key BCTs during trial.

Accept Keep and show historical target lines, and traffic light system in response to the specific targets at a specific time-point.

Accept Some initial problems with the pairing of devices caused some issues with data at the beginning of the pilot trial. High quality control to ensure effective pairing. Some cases the data appeared correct. Created further training and protocols on missing data and how interventionists should response to scenarios in which the validity of data was questioned.

Accept Inclusion of 'talking heads' videos made an optional part of the intervention. 
Table 6 Final intervention BCTs and mode of delivery

\begin{tabular}{|c|c|c|}
\hline Module & BCTs & Mode of delivery \\
\hline My treatment & $\begin{array}{l}4.1 \text { Instruction on how to perform } \\
\text { the behaviour } \\
5.1 \text { Information about health } \\
\text { consequences } \\
\text { 9.1 Credible source } \\
\text { 5.2 Salience of consequences } \\
\text { 6.1 Demonstration of the } \\
\text { behaviour } \\
\text { 16.3 Vicarious consequences } \\
\text { 15.4 Self-talk }\end{array}$ & $\begin{array}{l}\text { CFHealthHub: } \\
\text { - Demonstration of techniques for nebuliser use, cleaning and treatment mixing } \\
\text { - Information about CF, the need for treatment, how each treatment works, and the importance } \\
\text { of adherence } \\
\text { - Information presented in a variety of ways though written text, patient stories, 'talking heads', } \\
\text { and animation videos, with links to external content including Cochrane reviews } \\
\text { - Range of different credible information sources including PWCF, Clinicians, links to scientific } \\
\text { papers } \\
\text { Interventionist: } \\
\text { - Interventionist introducing and highlighting relevant content on CFHealthHub } \\
\text { - Interventionist eliciting self-talk through discussion of motivation }\end{array}$ \\
\hline Self-monitoring & $\begin{array}{l}\text { 2.2 Feedback on behaviour } \\
2.3 \text { Self-monitoring of behaviour } \\
12.5 \text { Adding objects to the } \\
\text { environment }\end{array}$ & $\begin{array}{l}\text { CFHealthHub } \\
\text { - Charts and tables of objective adherence data presented within CFHealthHub } \\
\text { Interventionist } \\
\text { - Introducing and explaining charts and tables to participants }\end{array}$ \\
\hline $\begin{array}{l}\text { Confidence } \\
\text { building }\end{array}$ & $\begin{array}{l}\text { 6.1 Demonstration of behaviour } \\
15.1 \text { Verbal persuasion about } \\
\text { capability } \\
15.3 \text { Focus on past success }\end{array}$ & $\begin{array}{l}\text { CFHealthHub } \\
\text { - Talking heads' videos of coping stories within CFHealthHub } \\
\text { Interventionist } \\
\text { - Interventionist encouraging focus on periods of higher adherence on charts }\end{array}$ \\
\hline $\begin{array}{l}\text { Goal setting } \\
\text { and review }\end{array}$ & $\begin{array}{l}\text { 1.1 Goal setting (behaviour) } \\
\text { 2.2 Feedback on behaviour } \\
\text { 1.6 Discrepancy between current } \\
\text { behaviour and goal } \\
\text { 1.5 Review behaviour goal } \\
\text { 8.7 Graded tasks } \\
\text { 10.4 Social reward }\end{array}$ & $\begin{array}{l}\text { CFHealthHub } \\
\text { - Indication of goal line on charts of adherence } \\
\text { - Visual indication of goal met on CFHealthHub } \\
\text { - (Optional) Weekly push notifications indicating whether goal was met } \\
\text { - (Optional) Reward messages sent when goal met } \\
\text { Interventionist } \\
\text { - Discussion and agreement of goals with interventionist } \\
\text { - Review of goals } \\
\text { - Suggested steady increase in goal as improvements are made } \\
\text { - Feedback and social reward on progress }\end{array}$ \\
\hline Treatment Plan & $\begin{array}{l}\text { 1.4 Action planning } \\
8.3 \text { Habit formation } \\
\text { 7.1 Prompts/cues }\end{array}$ & $\begin{array}{l}\text { CFHealthHub } \\
\text { - Action planning tool and storage within CFHealthHub } \\
\text { Interventionist } \\
\text { - Help to focus on identifying consistent cues and linking to behaviour (habit formation) } \\
\text { - Discussion and identification of appropriate cues - and how to add to the environment (if } \\
\text { necessary) }\end{array}$ \\
\hline $\begin{array}{l}\text { Problem- } \\
\text { solving }\end{array}$ & $\begin{array}{l}\text { 1.2 Problem solving } \\
\text { 12.1 Restructure the physical } \\
\text { environment } \\
\text { 15.4 Self-talk } \\
\text { 3.2 Social support (practical) } \\
\text { 4.1 Instruction on how to perform } \\
\text { the behaviour } \\
\text { 6.1 Demonstration of the } \\
\text { behaviour } \\
\text { 8.1 Behavioural practice/rehearsal }\end{array}$ & $\begin{array}{l}\text { CFHealthHub } \\
\text { - Solution bank within CFHealthhub (including advice to problem solve, restructure the physical } \\
\text { environment, engage social support) } \\
\text { - Coping planning, day planner, and party planner tools and storage within CFHealthHub } \\
\text { - Videos demonstrating correct use of nebulisers within CFHealthHub } \\
\text { Interventionist } \\
\text { - Tailored problem-solving guided by interventionist } \\
\text { - Support to create day plans/party plans where appropriate } \\
\text { - Support to construct if-then coping plans including identifying self-talk where appropriate }\end{array}$ \\
\hline
\end{tabular}

further development of the intervention and how they were responded to in subsequent developments are described in Table 5, and the final intervention that was used in the randomised controlled trial are described in Table 6.

The intervention manual was revised to address the identified need for change and to include information about the CFHealthHub mobile apps (iOS and Android) and associated functions. We developed worksheets for interventionists to follow during delivery of the intervention sessions. These worksheets included step by step instructions about how to interact with the CFHH content and the participant and included hints about how to phrase questions. An example worksheet for the first intervention visit is included in supplementary files. The associated training programme for interventionists was revised to be delivered in 2 face-to-face training days with 4 days of independent online training delivered via a virtual learning environment and ongoing tutorial support.

Modifications and adjustments to how the intervention was tailored and personalised were also considered and these are described in Tables 7 and 8 .

\section{Discussion}

The CFHealthHub intervention which comprised a digital platform and delivery by a health professional 
Table 7 Tailoring of the intervention components to meet specific participant needs

\begin{tabular}{l} 
Tailored component \\
\hline Contents of 'My treatment' and 'Problem-solving' \\
focus on information relevant to current \\
prescription drugs. \\
Modules of 'My treatment' are selected and \\
placed into 'My Toolkit' based on the scores on \\
the BMQ-Specific [38] questionnaire with one \\
additional item
\end{tabular}
How are non-tailored components accessed

All generic information in available to all participants to browse. Information on treatments not currently prescribed are available but minimised.

Participants can browse all modules of 'My treatment'. additional item ${ }^{\text {a. }}$
Modules of 'Problem-solving' are selected and placed into 'My Toolkit' based on the barriers identified in consultations with the interventionist.

'Talking heads' videos are selected to match key participant characteristics and placed into 'My Toolkit'. This is optional.
Goal setting and review and treatment planning are only utilised for participants who are motivated (want to) take more treatment. Participants with very low motivation do not receive these parts of the intervention. Instead they spend more time focusing on the content of 'My treatment' and relationship building with the interventionist.
Participants can browse all modules of 'Problem-solving'.

Participants can browse the entire 'talking heads' video library.

\section{How version is determined}

Prescription is entered into CFHealthHub at consent and altered whenever there is a prescription change. CFHealthhub automatically tailors content based on this information.

Participants' responses to the BMQ questionnaire [38] are entered into CFHealthHub at consent. CFHealthHub recommends the most relevant modules based on a scoring algorithm. If CFHealthHub recommends more than three modules then interventionists select three based on the scores and their judgement based on conversations with the participant. Modules can be changed throughout the intervention and these are recorded via CFHealthHub.

Interventionists can select modules of problemsolving content based on the barriers identified in consultations. Modules can be changed throughout the intervention and these are recorded via CFHealthHub.

Interventionists can select relevant videos that match key characteristics of the participant (e.g. age, gender, occupation, life role, problems experienced). Videos can be changed throughout the intervention and these are recorded via CFHealthHub.

Participants can choose to set goals and make plans at any point in a consultation or by contacting the interventionist.
Very low motivation is determined by a combination of a low motivation score on a questionnaire item and discussion with the participant in a consultation. The identification of very low motivation is recorded where this applies.

${ }^{a}$ We added the following item to the BMQ-Specific questionnaire based on our qualitative work about treatment beliefs: Nebulised antibiotic treatments are more important for my health than IV antibiotics (strongly agree to strongly disagree)

Table 8 Personalisation of the Intervention

\begin{tabular}{ll}
\hline Personalised component & How personalisation is achieved \\
\hline $\begin{array}{l}\text { Graphs and charts show } \\
\text { personal data }\end{array}$ & Participants eTrack nebuliser collects and send adherence data to CFHealthHub via the Qualcomm hub for display. \\
$\begin{array}{l}\text { Target line on graph } \\
\text { Plans }\end{array}$ & $\begin{array}{l}\text { Participants determine their adherence goal in consultation with the interventionist. This is displayed on their charts. } \\
\text { Participants make individual plans based on discussions with the interventionist. These are made using the tools } \\
\text { within CFHealthHub and recorded in 'My Toolkit'. New plans can be added and CFHealthHub records all plans for } \\
\text { each participant. }\end{array}$ \\
& $\begin{array}{l}\text { Participants can select an image to display on their home page from a default selection, or can upload their own } \\
\text { image. }\end{array}$ \\
& $\begin{array}{l}\text { Participants can optionally choose to receive personalised notifications via the CFHealthHub app. These send a } \\
\text { message to let the participant if they have met their goal in the previous week, they have met their goal on most } \\
\text { days in the previous week, or an encouraging messaging to keep going if they did not. }\end{array}$ \\
& $\begin{array}{l}\text { Participants can optionally choose to receive reminders via the CFHealthHub app. These send a reminder message if } \\
\text { the participant has not accessed their CFHealthHub account for a period of 2 weeks. } \\
\text { Reward messages are displayed on the CFHealthHub website or mobile app following log-in if the participant had } \\
\text { Reminders } \\
\text { Reward messages } \\
\text { been received for the last } 7 \text { consecutive days. }\end{array}$ \\
\hline
\end{tabular}


(with an associated manual and training) was developed through a rigorous and systematic development process. It was shown to be usable and acceptable to people with $\mathrm{CF}$ and the clinical community. Our development work demonstrated that inhalation data could be automatically transferred from a third party nebuliser device and displayed, in combination with prescription data, to provide visibility of a participant's adherence in real-life settings. Participants and clinicians were able to understand and interpret the data display quickly and easily. The intervention includes behaviour change techniques to address adherence to nebuliser treatment in people with $\mathrm{CF}$, which we have been able to tailor and personalise, so that it is appropriate for people with a range of different barriers to adherence.

A key value of our approach is that it has incorporated theory- and evidence-based approaches (Behaviour Change Wheel $[22,23])$ and target population-based approaches (person-based approach [24, 31]) [21]. Throughout the development process, we have been responsive to feedback and have changed and refined the intervention and the way in which it is delivered. The iterative process allowed issues to be identified quickly and updated rapidly, often during the early design phases, which minimised the cost and resources required to make the changes. Whilst pilot and feasibility studies are often considered to be outside of the intervention development process $[44,54]$, we utilised this opportunity to make further refinements to the intervention and its implementation in readiness for the full randomised controlled trial. We anticipate that the refinement process will continue following the randomised controlled trial and process evaluation in which it is currently being tested (trial registration, ISRCTN55504164) to inform implementation in clinical practice (trial registration, ISRCTN14464661).

Models for intervention development offer a pathway for intervention development but not a solution. Multiple decisions have to be made along the way, and the way in which they are made and the rationale behind those decisions depends in part on the intervention development team and their skills, experiences and expertise. The APEASE criteria [22] informed decisions and MoSCoW [58] enabled us to prioritise later changes, but the information that fed into the assessment of those criteria required the expertise of the development team. Ideas that seemed practical from the perspective of a health psychologist were not always practical from the perspective of a computer scientist. In addition, in terms of the likely effectiveness of the selected components, this required reference to our conceptual framework (see Fig. 1) and a good understanding of the theories and principles that underpinned different aspects of it; thus, the intervention drew on a range of different theories and evidence. The My treatment module (see Table
7) reflected the necessity-concerns framework [38], given that knowledge and beliefs about the consequences of treatment largely related to perceptions about the necessities and concerns for nebuliser treatment and social cognitive theory $[60,61]$ in terms of the role of outcome expectancies in behaviour. Confidence building also drew on social cognitive theory, employing a number of established strategies to increase self-efficacy (mastery, vicarious experiences, etc.). The self-monitoring, goal setting and planning modules drew on control theory [62], to explain how increased awareness of adherence behaviour and the identification of a discrepancy between current behaviour and goal might result in self-regulated behaviour change through action planning. Habit theory [42, 63] influenced the structure of action planning used in the intervention, i.e. the identification of a cue or prompt for nebuliser treatment and the use of an implementation intention [64] if cue then nebuliser treatmentbased action plan. Coping plans were used as part of problem solving [65] in order to address the issue of capability and opportunity barriers to treatment adherence and to help maintain adherence [43].

The development process was highly dependent on multidisciplinary working involving a team comprised of academics, clinicians, patients with CF, research software engineers, and UX designers. There were varying levels of understanding and experience of each other's roles, working practices, and workload. The initial model was based on obtaining and analysing participant feedback, agreeing design and software development requirements followed by development sprints, giving a new release of $\mathrm{CFHH}$ for each cycle of participants. However, difficulties in providing qualitative feedback in a timely manner identified previously [66] and the time required for design changes, programming, and testing meant this was not a viable working model. Regular meetings to facilitate clear communication, less technical and clinical language, and patience were required in order to develop the intervention, and many of the desired changes required significant development time such that some of the changes identified in stage 2 of the process were not actually included in the CFHealthHub digital platform until the beginning of the RCT. We recommend that future projects have early and ongoing team discussions so that expectations from all involved parties are realistic.

\section{Limitations}

There are some limitations of the approach. The data that informed stages 1 and 3 of the process stemmed from patients and clinicians from a single CF centre, and in stage 5 (the pilot study), from a further two centres and their associated clinical teams. This means that the intervention was based on a relatively small sample, and it is feasible that these centres may have differed from 
others in key ways, not least of which might have been high levels of motivation, and the clear commitment of the principal investigators at each site. The intervention development process was driven by a particular development team, made up of a particular mix of skills and expertise, and it is conceivable that a different team with different members may have made different decisions and arrived at a very different intervention. Whilst the input from patients, clinicians, and the multidisciplinary team was valuable, the process was resource and time intensive.

The intervention that we have developed is a complex one with multiple components tailored to meet the needs of different patients. Whilst this is a potential strength, it is also a potential limitation in that intervention delivery is quite long, and selection of the appropriate components for a particular patient relies on the skills and training of the interventionist. An alternative approach would have been to focus on one aspect of need (e.g. planning and habit formation) and develop an intervention just focused on these components. However, this would have meant that the intervention was not suitable for patients with lower motivation. Given that this group is of particular concern to clinicians (because they tend to be the least well), we felt that it would not be equitable or acceptable to design an intervention which did not target adherence increases across different patient groups. Following the RCT, we will be able to undertake analysis to explore which aspects of the intervention produced the intended changes in process outcomes and which did not, and if there are particular groups of patients for whom the intervention worked more or less well. This will enable us to pare down and refine the intervention further so that in the future, the intervention can be more tailored and can incorporate just those components found to be successful in improving adherence and this will likely reduce the length and complexity.

The initial qualitative work undertaken in stage 1 indicated that for patients, nebuliser use was seen as an integral part of their CF treatment alongside chest physiotherapy, diet, and enzymatic treatment for digestive issues, and for many patients, other treatments for co-morbid conditions including diabetes and liver conditions. It was beyond the scope of this programme of work to develop a system that could support adherence to all of these aspects of care.

\section{Conclusion}

We have devised an intervention to increase adherence to nebuliser treatment in adults with $\mathrm{CF}$ with substantial input from patients and clinicians and which has a strong theoretical and evidence base. The intervention comprised a digital platform (www.cfhealthhub.com) and components delivered in patient consultations with an interventionist. It is usable and acceptable to people with CF and clinicians. The intervention is currently being tested in a randomised controlled trial across 19 UK sites.

\section{Supplementary Information}

The online version contains supplementary material available at https://doi. org/10.1186/s40814-020-00739-2.

Additional file 1. First Intervention Visit: Worksheet

\begin{abstract}
Abbreviations
APEASE: Affordability, Practicability, Effectiveness/Cost-effectiveness,

Acceptability, Side-effects/Safety, Equity; BCTs: Behaviour change techniques; BCW: Behaviour Change Wheel; CF: Cystic fibrosis; CFHH: CFHealthHub; COMB: Capability, opportunity, and motivation-behaviour; MDT: Multidisciplinary team; MoSCoW: Must have, should have, could have, won't have; PBA: Person-based approach; PPI: Patient and public involvement; RCT: Randomised controlled trial; TiDieR: Template for Intervention Description and Replication; TDF: Theoretical domains framework
\end{abstract}

\section{Acknowledgements}

We would like to thank Professor Susan Michie who provided helpful feedback on the Behaviour Change Wheel mapping stage of the process; and the clinicians and patients who took the time to provide feedback during intervention conception and development without whom this work could not have taken place. We would like to acknowledge the UX research and design input provided by Ricardo Ortega of KeepltUsable, who developed the early front-end designs of the CFHealthHub website and apps.

\section{Authors' contributions}

MA (Professor of Health Psychology), SD (Research Associate), PW (Digital Health Software Lead), MH (Physiotherapist) and DB (Patient and Public Involvement Representative) drafted the report. The following designed the research: MW (Consultant Respiratory Physician), AO (Professor of Health Services Research), MA, SD, PW, MH, JB (Professor of Physiotherapy), DH (Assistant Director of Clinical Trials Research Unit), and JA (Professor of Health Informatics). The following were involved in acquisition of data for the work: SD, MH, CM (Study Manager), HC (Study Manager), MA, and PW. The following were involved in the analysis and interpretation of the data: MA, $\mathrm{SD}, \mathrm{MH}, \mathrm{MW}, \mathrm{AO}, \mathrm{PW}, \mathrm{DB}, \mathrm{JB}, \mathrm{CM}, \mathrm{HC}$, and $\mathrm{DH}$. The following designed the intervention software, tools and manuals/training: MA, MH, PW, JA, and JB. All authors were involved in the final approval of the version to be published. All authors agree to be accountable for all aspects of the work in ensuring that questions related to the accuracy or integrity of any part of the work are appropriately investigated and resolved.

\section{Funding}

This study/project is funded by the National Institute for Health Research (NIHR) [ACtiF Programme (reference RP-PG-1212-20015)] Programme Grants for Applied Research. The views expressed are those of the authors and not necessarily those of the NIHR or the Department of Health and Social Care.

\section{Availability of data and materials}

The datasets used and/or analysed during the current study are available from the corresponding author on reasonable request.

\section{Ethics approval and consent to participate}

Ethical approval was gained for all studies: from the Yorkshire and Humber ethics committee [REC reference 15/YH/0332] and West of Scotland ethics committee [REC reference 15/WS/0089]. All participants gave written informed consent.

Consent for publication

Not applicable 


\section{Competing interests}

Martin Wildman received funding from Zambon and support from Philips Respironics for the early development work. This has not had any direct influence on the study reported here. Martin Wildman has worked with Pari to carry out studies using the eTrack. This has not had any direct influence on the study reported here. The University of Manchester software team received funding from Pari to create a medication reporting component within the CFHealthHub software. This has not had any direct influence on the study reported here.

The other authors declare that they have no competing interests.

\section{Author details}

'Centre for Behavioural Science and Applied Psychology, Sheffield Hallam University, 2.03a Heart of the Campus, Collegiate Crescent Campus, Sheffield S10 2BQ, UK. ${ }^{2}$ Sheffield Adult Cystic Fibrosis Unit Sheffield Teaching Hospitals NHS Foundation Trust, Northern General Hospital, Herries Road, Sheffield S5 7AU, UK. ${ }^{3}$ Health eResearch Centre-Farr Institute, Division of Imaging, Informatics and Data Sciences, School of Health Sciences, Faculty of Biology, Medicine and Health, The University of Manchester, Manchester Academic Health Science Centre, Manchester M13 9GB, UK. ${ }^{4}$ School of Health and Related Research, University of Sheffield, Regent Court, 30 Regent Street, Sheffield S1 4DA, UK. ${ }^{5}$ Clinical Trials Research Unit, University of Sheffield, Regent Court, 30 Regent Street, Sheffield S1 4DA, UK. ${ }^{6}$ Centre for Experimental Medicine, School of Medicine, Dentistry and Biomedical Sciences, Queen's University, 97 Lisburn Road, Belfast BT9 7BL, UK.

Received: 20 February 2020 Accepted: 30 November 2020 Published online: 04 January 2021

\section{References}

1. Cystic Fibrosis Trust [Internet] London, UK: What is cystic fibrosis? [cited 2019 Nov 18] Available from https://www.cysticfibrosis.org.uk/what-is-cysticfibrosis.

2. O'Sullivan B, Freedman S. Cystic fibrosis. The Lancet. 2009;373(9678):1891904.

3. Sawicki G, Sellers D, Robinson W. High treatment burden in adults with cystic fibrosis: challenges to disease self-management. Journal of Cystic Fibrosis. 2009;8(2):91-6.

4. Sawicki G, Tiddens H. Managing treatment complexity in cystic fibrosis: challenges and opportunities. Pediatric Pulmonology. 2012;47(6):523-33.

5. Daniels T, Goodacre L, Sutton C, Pollard K, Conway S, Peckham D. Accurate assessment of adherence. Chest. 2011;140(2):425-32.

6. Eakin M, Bilderback A, Boyle M, Mogayzel P, Riekert K. Longitudinal association between medication adherence and lung health in people with cystic fibrosis. Journal of Cystic Fibrosis. 2011;10(4):258-64.

7. Hoo ZH, Curley R, Walters SJ, Campbell MJ, Wildman MJ. Exploring the implications of different approaches to estimate centre-level adherence using objective adherence data in an adult cystic fibrosis centre-a retrospective observational study. J Cystic Fibrosis. 2019.

8. Briesacher BA, Quittner AL, Saiman L, Sacco P, Fouayzi H, Quittell LM. Adherence with tobramycin inhaled solution and health care utilization. BMC pulmonary medicine. 2011 Dec;11(1):5.

9. Hoo Z, Campbell MJ, Curley R, Wildman MJ. Rescue and prevention in cystic fibrosis: an exploration of the impact of adherence to preventative nebulised therapy upon subsequent rescue therapy with IV antibiotics in adults with CF. InJournal of Cystic Fibrosis. 2016;15(Suppl 1):S120 Elsevier.

10. Quittner AL, Zhang J, Marynchenko M, Chopra PA, Signorovitch J, Yushkina $Y$, Riekert KA. Pulmonary medication adherence and health-care use in cystic fibrosis. Chest. 2014 Jul 1;146(1):142-51.

11. White H, Shaw N, Denman S, Pollard K, Wynne S, Peckham DG. Variation in lung function as a marker of adherence to oral and inhaled medication in cystic fibrosis. European Respiratory Journal. 2017 Mar 1;49(3):1600987.

12. Quittner AL, Saez-Flores E, Barton JD. The psychological burden of cystic fibrosis. Current opinion in pulmonary medicine. 2016 Mar 1:22(2):187-91.

13. Goldbeck L, Fidika A, Herle M, Quittner A. Psychological interventions for individuals with cystic fibrosis and their families. Cochrane Database of Syst Rev. 2014

14. Quittner AL, Eakin MN, Alpern AN, Ridge AK, McLean KA, Bilderback A Criado KK, Chung SE, Riekert KA. Clustered randomized controlled trial of a clinic-based problem-solving intervention to improve adherence in adolescents with cystic fibrosis. Journal of Cystic Fibrosis. 2019.
15. Jones S, Curley R, Wildman M, Morton RW, Elphick HE. Interventions for improving adherence to treatment in cystic fibrosis. Cochrane database of systematic reviews. 2015;4.

16. Craig P, Dieppe P, Macintyre S, Michie S, Nazareth I, Petticrew M. Developing and evaluating complex interventions: the new Medical Research Council quidance. Bmj. 2008 Sep 29;337:a1655.

17. Michie S, Prestwich A. Are interventions theory-based? Development of a theory coding scheme. Health psychology. 2010 Jan;29(1):1.

18. Easthall C, Barnett N. Using theory to explore the determinants of medication adherence; moving away from a one-size-fits-all approach. Pharmacy. 2017 Sep;5(3):50.

19. Ivers N, Jamtvedt G, Flottorp S, Young JM, Odgaard-Jensen J, French SD, O'Brien MA, Johansen M, Grimshaw J, Oxman AD. Audit and feedback: effects on professional practice and healthcare outcomes. Cochrane database of systematic reviews. 2012;6.

20. Ivers NM, Grimshaw JM, Jamtvedt G, Flottorp S, O'Brien MA, French SD, Young J, Odgaard-Jensen J. Growing literature, stagnant science? Systematic review, meta-regression and cumulative analysis of audit and feedback interventions in health care. Journal of general internal medicine. 2014 Nov 1;29(11):1534-41.

21. O'Cathain A, Croot L, Sworn K, Duncan E, Rousseau N, Turner K, Yardley L, Hoddinott P. Taxonomy of approaches to developing interventions to improve health: a systematic methods overview. Pilot and feasibility studies. 2019 Dec;5(1):41.

22. Michie S, Van Stralen MM, West R. The behaviour change wheel: a new method for characterising and designing behaviour change interventions. Implementation science. 2011 Dec;6(1):42.

23. Michie S, Atkins L, West R. The behaviour change wheel. A guide to designing interventions. 1st ed. Great Britain: Silverback Publishing; 2014. p. 1003-10.

24. Yardley L, Morrison L, Bradbury K, Muller I. The person-based approach to intervention development: application to digital health-related behavior change interventions. J Med Internet Res. 2015;17(1):e30.

25. Bowers HM, Kendrick T, Glowacka M, Williams S, Leydon G, May C, Dowrick C, Moncrieff J, Laine R, Nestoriuc Y, Andersson G. Supporting antidepressant discontinuation: the development and optimisation of a digital intervention for patients in UK primary care using a theory, evidence and person-based approach. BMJ open. 2020;10(3):e032312.

26. Cane J, O'Connor D, Michie S. Validation of the theoretical domains framework for use in behaviour change and implementation research. Implementation science. 2012 Dec;7(1):37.

27. French SD, Green SE, O'Connor DA, McKenzie JE, Francis JJ, Michie S, et al. Developing theory-informed behaviour change interventions to implement evidence into practice: a systematic approach using the Theoretical Domains Framework. Implement Sci. 2012;7:38.

28. Atkins L, Michie S. Changing eating behaviour: what can we learn from behavioural science? Nutrition Bulletin. 2013 Mar;38(1):30-5.

29. Michie S, Richardson M, Johnston M, Abraham C, Francis J, Hardeman W, Eccles MP, Cane J, Wood CE. The behavior change technique taxonomy (V1) of 93 hierarchically clustered techniques: building an international consensus for the reporting of behavior change interventions. Annals of behavioral medicine. 2013;46(1):81-95.

30. Barker F, Atkins L, de Lusignan S. Applying the COM-B behaviour model and behaviour change wheel to develop an intervention to improve hearing-aid use in adult auditory rehabilitation. International journal of audiology. 2016; 55(sup3):S90-8.

31. Chiang N, Guo M, Amico KR, Atkins L, Lester RT. Interactive two-way mHealth interventions for improving medication adherence: an evaluation using the behaviour change wheel framework. JMIR mHealth and uHealth. 2018;6(4):e87.

32. Barach $\mathrm{P}$, Johnson JK. Understanding the complexity of redesigning care around the clinical microsystem. Qual Saf Heal Care. 2006;15(suppl_1):110-6.

33. Hoo Z, Gardner B, Curley R, Wildman M. Part I : Understanding the variation in adherence with nebulised treatment in cystic fibrosis. J Improv Sci. 2013; 9(January):1-10.

34. Wildman MJ, Hoo ZH. Moving cystic fibrosis care from rescue to prevention by embedding adherence measurement in routine care. Paediatr Respir Rev. 2014;15(S1):16-8.

35. Hoo ZH, Curley R, Campbell MJ, Walters SJ, Hind D, Wildman MJ. Accurate reporting of adherence to inhaled therapies in adults with cystic fibrosis: methods to calculate normative adherence. Patient Prefer Adherence. 2016;887. 
36. Milne A, Rose C, Thornton S, Curley R, Hoo ZH, Wildman M. 275 understanding barriers to weight gain, nebuliser use and exercise in CF. J Cyst Fibros. 2014;13:S118.

37. Jones S, Babiker N, Gardner E, Royle J, Curley R, Hoo ZH, et al. Promoting adherence to nebulized therapy in cystic fibrosis: poster development and a qualitative exploration of adherence. Patient Prefer Adherence. 2015:9:1109-20.

38. Horne R, Weinman J, Hankins M. The beliefs about medicines questionnaire: the development and evaluation of a new method for assessing the cognitive representation of medication. Psychology and health. 1999 Jan 1; 14(1):1-24.

39. Rothman, A. J., Baldwin, A. S., Hertel, A. W., \& Fuglestad, P. T. Self-regulation and behavior change: disentangling behavioral initiation and behavioral maintenance. In K. D. Vohs \& R. F. Baumeister (Eds.), Handbook of selfregulation: Research, theory, and applications 2011(pp. 106-122). New York, NY, US: Guilford Press.

40. Baumeister RF, Heatherton TF. Self-regulation failure: an overview. Psychological inquiry. 1996 Jan 1;7(1):1-5.

41. Hall PA, Fong GT. Temporal self-regulation theory: a model for individual health behavior. Health Psychology Review. 2007 Mar 1;1(1):6-52.

42. Gardner B, Rebar AL. Habit formation and behavior change. In Oxford Research Encyclopedia of Psychology; 2019

43. Kwasnicka D, Dombrowski SU, White M, Sniehotta F. Theoretical explanations for maintenance of behaviour change: a systematic review of behaviour theories. Health Psychology Rev. 2016s;10(3):277-96.

44. O'Cathain A, Croot L, Duncan E, Rousseau N, Sworn K, Turner KM, Yardley L, Hoddinott P. Guidance on how to develop complex interventions to improve health and healthcare. BMJ open. 2019 Aug 1:9(8):e029954.

45. Highsmith J. Agile project management: creating innovative products. Pearson education; 2009.

46. King's Fund. The health care workforce in England: make or break?.2018. Nov. https://www.kingsfund.org.uk/sites/default/files/2018-11/The\%2 Ohealth\%20care\%20workforce\%20in\%20England.pdf.

47. Jones S, Curley R, Wildman M. 345 Systematic review of qualitative studies investigating barriers to adherence in patients with cystic fibrosis using framework analysis structured by a conceptual framework of behaviour change. Journal of Cystic Fibrosis. 2013 Jun 1;12:S136.

48. Sawicki GS, Heller KS, Demars N, Robinson WM. Motivating adherence among adolescents with cystic fibrosis: youth and parent perspectives. Pediatric Pulmonology. 2015 Feb;50(2):127-36.

49. Kwasnicka D, Dombrowski SU, White M, Sniehotta F. Theoretical explanations for maintenance of behaviour change: a systematic review of behaviour theories. Health psychology review. 2016 Jul 2;10(3):277-96.

50. Arden MA, Drabble S, O'Cathain A, Hutchings M, Wildman M. Adherence to medication in adults with cystic fibrosis: an investigation using objective adherence data and the theoretical domains framework. Brit J of Health Psychol. 2019;24(2):357-80.

51. Drabble SJ, O'Cathain A, Arden MA, Hutchings M, Beever D, Wildman M When is forgetting not forgetting? A discursive analysis of differences in forgetting talk between adults with cystic fibrosis with different levels of adherence to nebulizer treatments. Qualitative health research. 2019 Jul;13: 1049732319856580.

52. Ericsson KA, Simon HA. How to study thinking in everyday life: contrasting think-aloud protocols with descriptions and explanations of thinking. Mind, Culture, and Activity. 1998 Jul 1;5(3):178-86.

53. Van den Haak MJ, De Jong MD, Schellens PJ. Evaluation of an informational web site: three variants of the think-aloud method compared. Technical Communication. 2007 Feb 1;54(1):58-71.

54. Hoddinott P. A new era for intervention development studies. Pilot and Feasibility Studies. 2015;1:36-6.

55. Hind D, Drabble SJ, Arden MA, Mandefield L, Waterhouse S, Maguire C, Cantrill H, Robinson L, Beever D, Scott AJ, Keating S. Supporting medication adherence for adults with cystic fibrosis: a randomised feasibility study. BMC pulmonary medicine. 2019 Dec;19(1):77.

56. Drabble SJ, O'Cathain A, Scott AJ, Arden MA, Keating SM, Hutchings M, Maguire C \& Wildman R. How the mechanisms of relationship, visibility, and fit operated in a web-based intervention with health professional support to increase nebulizer adherence in adults with CF: a qualitative process evaluation study of a pilot randomized controlled trial. Journal of Medical Internet Research. Under review.

57. O'Cathain A, Murphy E, Nicholl J. Three techniques for integrating data in mixed methods studies. Bmj. 2010 Sep 17;341:C4587.
58. Clegg D, Barker R. Case method fast-track: a RAD approach: Addison-Wesley Longman Publishing Co, Inc..; 1994.

59. Hoffmann TC, Glasziou PP, Boutron I, Milne R, Perera R, Moher D, Altman DG, Barbour V, Macdonald H, Johnston M, Lamb SE. Better reporting of interventions: template for intervention description and replication (TIDieR) checklist and guide. Bmj. 2014 Mar 7;348:g1687.

60. Bandura A. Social foundations of thought and action. Englewood Cliffs, NJ; 1986.

61. Bandura A. Social cognitive theory of self-regulation. Organizational behavior and human decision processes. 1991 Dec 1;50(2):248-87.

62. Carver CS, Scheier MF. Control theory: a useful conceptual framework for personality-social, clinical, and health psychology. Psychological bulletin. 1982 Jul;92(1):111.

63. Gardner B. A review and analysis of the use of 'habit' in understanding, predicting and influencing health-related behaviour. Health psychology review. 2015 Aug 7;9(3):277-95

64. Gollwitzer PM. Implementation intentions: strong effects of simple plans. American psychologist. 1999 Jul;54(7):493.

65. Sniehotta FF, Schwarzer R, Scholz U, Schüz B. Action planning and coping planning for long-term lifestyle change: theory and assessment. European Journal of Social Psychology. 2005 Jul;35(4):565-76.

66. Drabble $\mathrm{SJ}, \& \mathrm{O}^{\prime}$ Cathain $\mathrm{A}$. Moving from randomised controlled trials to mixed methods intervention evaluations in Hesse-Biber S, \& Johnson B (eds. ) Oxford Handbook of Mixed and Multimethod Research Inquiry. Oxford University Press. 2015.

\section{Publisher's Note}

Springer Nature remains neutral with regard to jurisdictional claims in published maps and institutional affiliations.
Ready to submit your research? Choose BMC and benefit from:

- fast, convenient online submission

- thorough peer review by experienced researchers in your field

- rapid publication on acceptance

- support for research data, including large and complex data types

- gold Open Access which fosters wider collaboration and increased citations

- maximum visibility for your research: over $100 \mathrm{M}$ website views per year

At BMC, research is always in progress.

Learn more biomedcentral.com/submissions 